This is the post print of the article. Please cite it in this form: Freixa J, Freixas M, Solivellas I.

Autonomia i heteronomia en la innovació lèxica catalana. Catalan Review. 2020;34(1):99-118. DOI:

10.3828/CATR.34.6

\title{
Autonomia i heteronomia en la innovació lèxica catalana ${ }^{i}$ \\ Judit Freixa, Martí Freixas i Ivan Solivellas \\ Universitat Pompeu Fabra (Barcelona)
}

\begin{abstract}
In this globalized age, it is a challenge for languages to denominate reality from its own perspective, and one of the consequences is that languages are towed in English, so languages look for an own denominative space, while joining the global denomination through linguistic loans. However, Freixa (2017) offers a new analysis perspective and provides data for Catalan that suggest that many neologisms, apparently trained with the rules of Catalan, are Spanish calques. For this reason, this work analyses a set of 4,200 Catalan lexicographic neologisms documented in the database of the Observatori de Neologia (OBNEO) of 2016 in order to find out which units are properly Catalan and which, on the contrary, are a Spanish loan translation. To avoid distortions of the corpus, we contrast the data with the Factiva corpus, in order to contrast the results obtained. From here, we describe the different degrees of lexical innovation in Catalan language to see if there is a tendency to loan or to innovate by its own.
\end{abstract}

Key Words: Catalan, sociolinguistics, lexical innovation, loan

\section{Introducció ${ }^{\mathrm{ii}}$}

És un repte per a les llengües d’Europa, per no dir les de tot el món, denominar la realitat des d'una perspectiva pròpia. Avui dia, i des de fa anys, la majoria d'escenaris comunicatius i de coneixement estan tan mundialitzats que la majoria de llengües van a remolc de l'anglès, denominativament parlant. De vegades perquè agafen directament les paraules de l'anglès $i$, en d'altres ocasions, perquè copien i tradueixen aquests mots. Quin 
percentatge de les paraules que han aparegut, per exemple, en la llengua sueca els darrers cinc anys són pròpiament sueques? Autènticament i genuïnament sueques? I en el cas del francès, el grec o el portuguès? La veritat és que no ho sabem, perquè no existeixen estudis en aquest sentit, però sí que sabem que algunes llengües, com el cas del català, no només intenten mantenir-se denominativament útils davant de la pressió de l'anglès, la lingua franca actual, sinó que a més han de resistir davant d'altres llengües amb les quals conviuen.

Aquest és el cas del català, una llengua que compta amb un Observatori de Neologia ${ }^{\text {iii }}$ des de l'any 1989 i que, per tant, compta amb elements sòlids per descriure'n la capacitat d'innovació lèxica amb perspectiva. El català és una d'aquestes llengües europees que lluita per mantenir la vitalitat lèxica pròpia davant la pressió denominativa d'altres llengües, en aquest cas del castellà, a banda de la de l'anglès.

En aquest article ens proposem de reflexionar sobre el paper real del català a l'hora de denominar tot allò que no s'havia hagut de denominar abans i que normalment ja arriba amb una denominació aliena. Així doncs, parlarem d'autonomia quan puguem demostrar que el català ha denominat lliurement i parlarem d'heteronomia quan no ho hagi fet, tant si ha optat pel manlleu, com si ha optat per una traducció. Però abans volem posar aquesta reflexió en el marc dels antecedents existents.

\section{Antecedents i aspectes teòrics}

La vitalitat de les llengües s'ha estudiat des de diferents perspectives i una és l'observació sociolingüística de la innovació lèxica, segons la qual és un signe de vitalitat que una llengua trobi mecanismes per actualitzar el lèxic (Cabré 2000, Humbley 2000). ${ }^{\text {iv }}$ Per això, diferents autors apunten que la neologia és un indicador de la vitalitat d'una llengua, en la mesura que «és un dels recursos que fan servir les llengües per garantir la seva continuïtat, i les llengües en procés de normalització per apuntalar la seva supervivència» (Cabré 2004: 
19). Contràriament, és un signe de falta de vitalitat que una llengua tingui el manlleu com a recurs principal (Cabré et al. 2000, Sinner 2006) en la mesura que s'entén que la llengua en qüestió no és capaç d'ampliar el cabal lèxic amb recursos propis. ${ }^{\mathrm{v}}$

D'aquesta manera podem visualitzar un eix amb dos pols: en un s'hi troba la innovació lèxica pròpia, que en aquest treball anomenem autonomia, i en l'altre, la innovació lèxica aliena, que anomenem heteronomia, i que es refereix a la innovació a partir del recurs principal del manlleu, així com del calc i els altres tipus d'interferències. Partim d'una concepció neutra del manlleu, en el sentit que ha estat sempre un recurs natural de les llengües i, doncs, és en el pes d'aquest recurs sobre el total de la innovació on el podem concebre com un signe de falta de vitalitat lèxica.

En l'àmbit català, s'han desenvolupat diversos estudis en aquest sentit (Cabré 2000, Cabré et al. 2000, Cabré et al. 2001) i darrerament Freixa (2017) ha incorporat el paràmetre «temps» per determinar el grau d'autonomia en la innovació lèxica. Contrastant la data de documentació de diversos neologismes en textos catalans amb la data de documentació dels mateixos neologismes en textos d'altres llengües —en aquest cas, el castellà-, Freixa (2017) afirma que molt sovint es pren com a innovació pròpia el que és traducció sistemàtica - i de vegades poc acceptable— dels neologismes d'altres llengües.

En aquest treball ens proposem de discutir aquesta afirmació amb un corpus de neologismes recents del català, reprenent la idea de l'eix de vitalitat lingüística de Cabré et al. (2000), però utilitzant els conceptes autonomia i heteronomia, presos de la terminologia de base sociolingüística i dialectològica (Trudgill 1986, Chambers i Trudgill 1998). 
Aquest eix mostra els dos pols propis de qualsevol llengua, en la mesura que totes innoven i copien. Tot i així, hi ha sistemes lingüístics que tendeixen a la innovació pròpia l'anglès en seria un clar exemple - i d'altres que tendeixen a ser influenciats per sistemes aliens - el màxim d'alienació possible seria que no existís cap mena d'innovació pròpia, moment en què la llengua ja s'hauria dissolt totalment en una altra. Com més autònoma sigui una llengua, més vitalitat lèxica mostrarà, de manera que augmentarà el cabal lèxic amb recursos propis, mentre que un sistema heterònom demostrarà una innovació lèxica amb més tendència al manlleu, el calc i la interferència en general. En el cas del català, mirarem d'establir el punt de l'eix on es troba actualment, perquè sabem que no està situat en cap dels dos pols, ja que com afirma Freixa (2015: 194) « [...] el català presenta símptomes clars d'interferència del castellà (i de l'anglès, en darrer terme), de la mateixa manera que presenta símptomes clars d'evolució natural de la llengua».

\section{Dades i metodologia}

Per tal d'analitzar la tendència a l'autonomia o a l'heteronomia de la llengua catalana, hem fet una anàlisi contrastiva entre el català i el castellà a partir d'un corpus constituït per 4.169 neologismes $^{\mathrm{vi}}$ obtinguts del buidatge de textos orals i escrits (premsa escrita $\mathrm{i}$ programes radiofònics) de l'any 2016. Per a cadascun d'aquests neologismes s'ha buscat la forma castellana ${ }^{\mathrm{vii}}$ i després s'ha fixat l'any de la primera documentació d'aquests neologismes (forma catalana i castellana) en la base de dades de l'OBNEO i Factiva. ${ }^{\text {viii }}$ S'ha assignat un codi per a cada neologisme (català) segons si s'ha documentat abans o després que en castellà, i també segons el lapse temporal. Com es pot veure en la taula 1, aquests codis (A, B, C, D i E) representen el que hem denominat categories de vitalitat lèxica.

\begin{tabular}{cl}
\hline Codi & Categoria de vitalitat lèxica \\
\hline A & documentat només en català \\
\hline B & documentat primer en català \\
\hline C & documentat igual en català i en castellà \\
\hline
\end{tabular}




\begin{tabular}{cc}
\hline D & documentat primer en castellà \\
\hline E & documentat en el DLE \\
\hline & Taula 1. Codis segons la categoria de vitalitat lèxica
\end{tabular}

El codi A es refereix als neologismes que només s'han documentat en català, situació que representa la màxima autonomia en la innovació lèxica - encara que existeixi una forma en castellà, no és una forma equivalent $\mathrm{i}$, per tant, considerem que el català no ha copiat, mentre que el codi $\mathbf{B}$ fa referència als neologismes que s'han documentat abans en català que en castellà i, doncs, també se situen en el pol de la innovació lèxica pròpia. En el centre de l'eix, que hem denominat punt de convergència, ${ }^{\text {ix }}$ hi ha els neologismes que s'han documentat al mateix temps en català i en castellà, ${ }^{x}$ representats pel codi C. Seguint l'eix cap al pol de l'heteronomia trobem el conjunt de neologismes que s'han documentat primer en castellà (codi D) i, finalment, en el pol de la innovació lèxica aliena i de la mínima vitalitat lèxica, hi ha els neologismes que no es documenten en castellà perquè ja figuren al Diccionario de la lengua española de la Real Academia Española (DLE) i, doncs, ja no es consideren neologismes quan apareixen en els textos analitzats (codi E). En aquest darrer cas, és de suposar que el mot en castellà es va començar a documentar abans que en català perquè ja ha culminat la seva trajectòria en l'ús i s'ha incorporat en el diccionari.

En la figura següent podem veure quina seria la situació per a una llengua en què l'autonomia i l'heteronomia tinguessin el mateix pes, és a dir, si les cinc categories de vitalitat possibles es repartissin equitativament.

Autonomia

+ vitalitat

\begin{tabular}{|c|c|c|c|c|}
\hline $20 \%$ & $20 \%$ & $20 \%$ & $20 \%$ & $20 \%$ \\
\hline
\end{tabular}

B

C

D

E

Figura 2. Distribució teòrica de l'eix de vitalitat lèxica

Tant l'eix de vitalitat lèxica que presentem aquí com els resultats que n'extraurem s'han d'entendre i interpretar tenint en compte les característiques i limitacions 
metodològiques següents que poden esbiaixar l'experiment: a) les dades de l'OBNEO no són absolutes i per al 2016 es van buidar gairebé el doble de textos catalans que castellans; $b$ ) el corpus Factiva és, en canvi, molt major en castellà que no en català i $c$ ) el contrast parteix de la llista de neologismes catalans $\mathrm{i}$, per tant, no hi ha ni la situació inversa del codi A — perquè no podem controlar els neologismes que s'han documentat en castellà i no en català- ni la situació inversa del codi $\mathrm{E}$ —neologismes castellans que ja hagin estat incorporats en les obres lexicogràfiques catalanes i, per tant, ja no es consideren neologismes en aquesta llengua.

Així doncs, i tenint en consideració que «el moment d'aparició a la premsa no marca definitivament el moment d'aparició en l'ús de la llengua» (Freixa 2017: 50), no pretenem aportar dades absolutes, exhaustives i definitives sobre la capacitat d'innovació lèxica del català, però sí que pretenem oferir una aproximació innovadora i amb una metodologia més afinada que les investigacions prèvies sobre aquesta qüestió.

\section{Resultats}

A continuació es mostren els resultats de la investigació. En primer lloc ens referim al percentatge de cadascuna de les categories de vitalitat (§ 4.1) i ens fixem en les diferències que s'observen en les diferents categories segons la freqüència i els processos d'innovació. En el segon bloc de resultats $(\S 4.2)$ analitzem les característiques principals de cadascuna de les categories de vitalitat.

\subsection{Resultats generals}

Si la distribució fos equilibrada, el bloc d'autonomia (codis A i B) sumaria el $40 \%$ del total, el bloc de convergència sumaria el $20 \%$ (codi C) i el bloc d'heteronomia sumaria un $40 \%$ (codis D i E), però com es pot veure a la figura 3 el resultat per al català amb les dades del 2016 tendeix fortament cap a l'heteronomia: el bloc d'heteronomia suma el 66,8\% del total, el bloc de convergència és del $15,9 \%$ i el d'autonomia representa només un $17 \%$. Observem 
també que el cas més freqüent, un $40,8 \%$, és que la forma castellana s'hagi documentat abans que la catalana (codi D) i el menys freqüent és que no es documenti la forma castellana, amb un $4,3 \%(\operatorname{codi} A)$.

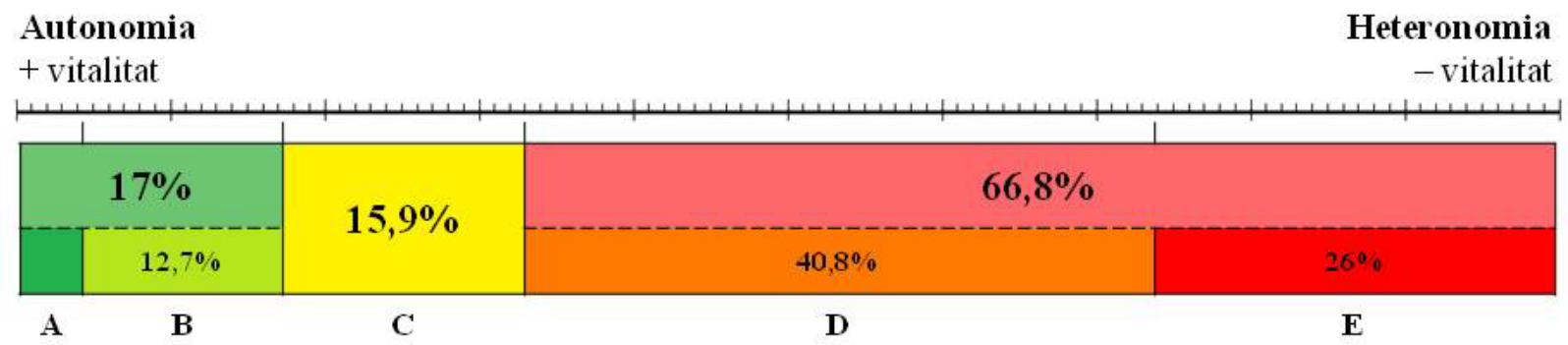

Figura 3. Eix d'autonomia a heteronomia per al català

Aquests resultats permeten afirmar que la innovació lèxica catalana és molt més aliena que no pas pròpia, i s'entendria com un resultat clarament negatiu només si partíssim de la base que el català ha de ser autònom — o més autònom que heterònom- en l'activitat neològica. Però, com hem dit a l'inici d'aquest treball, les llengües d'avui dia lluiten per trobar un espai denominatiu propi, encara que sigui reduït, en el món globalitzat actual. Un espai que permeti a la llengua mantenir l'ús de les regles de formació pròpies, no només des d'un punt de vista morfològic — perquè en el calc hi podem veure una utilització de les regles pròpies, encara que sigui passiva—, sinó també semàntic — perquè el calc comporta també una visió del món copiada, perquè es copia també la motivació semàntica. Amb aquesta perspectiva, podem llegir els resultats d'una manera més optimista i considerar un fet positiu que el 15,9\% dels neologismes del 2016 es documentin al mateix temps en català i en castellà, perquè això és un símptoma d'autonomia del català respecte del castellà, tot i que segurament indica heteronomia respecte de l'anglès. I, encara més, cal donar-li el valor que es mereix al $12,7 \%$ de neologismes que es documenten en català abans que en castellà. Quant al 4,3\% d'autonomia absoluta, cal reconèixer el seu caràcter simbòlic.

\begin{tabular}{ll}
\hline A & comsemprisme, taradellejar, pseudoovni, marranor, tofonada \\
\hline B & anticonformista, burricleta, neopolar, presentisme, pujolià \\
\hline C & euroordre, marca blanca, parkour, tauleta, whatsapp \\
\hline
\end{tabular}




\begin{tabular}{ll}
\hline $\mathbf{D}$ & customitzar, equinoteràpia, micromasclisme, paintball, transmèdia \\
\hline $\mathbf{E}$ & airbag, engominar, mileurista, superheroi, tutoritzar \\
\hline
\end{tabular}

Taula 2. Exemples de neologismes catalans segons la categoria de vitalitat lèxica

Els exemples de la taula 2 permeten percebre algunes tendències clares que tractarem més endavant (§ 4.2). Així doncs, els neologismes de cada categoria presenten característiques diferents des del punt de vista pragmàtic, morfològic i temàtic, però també en altres aspectes, com l'estabilització en l'ús.

\section{Desviacions de freqüència}

La figura 4 indica el percentatge de neologismes de cada categoria de vitalitat lèxica segons el nombre d'ocurrències, com s'indica en la llegenda: una (hàpax), dues, entre tres i cinc, i més de cinc ocurrències. Les diferents barres horitzontals permeten veure les desviacions de cada categoria respecte de les dades globals (a la barra inferior). El primer que cal subratllar és el percentatge elevat d'hàpaxs en totes les categories, cosa que indica el baix nivell d'estabilitat d'un nombre altíssim de neologismes que apareixen en el corpus.

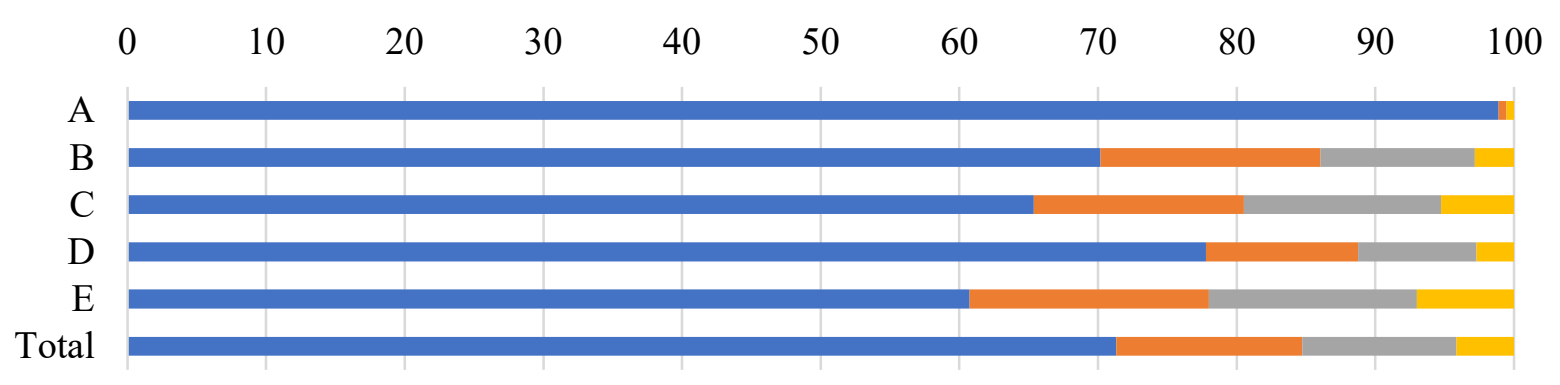

$$
\square \mathrm{F} 1 \quad \mathrm{~F} 2 \quad \mathrm{~F} 3-5 \square \mathrm{F}<5
$$

Figura 4. Contrastos de freqüència entre les diferents categories de vitalitat lèxica

Si ens fixem en les desviacions respecte del comportament global dels neologismes, veiem que els neologismes amb la freqüència mínima d'una sola ocurrència (hàpaxs) representen el 71,3\% del total, però en els exemples més autònoms (codi $\mathrm{A}$ ) puja fins al 98,9\%; en canvi, en la categoria B (la primera documentació és en català) el percentatge d'hàpaxs pràcticament no es desvia del resultat global $(70,1 \%)$ i les categories més heterònomes (D i E) presenten oscil·lacions inverses respecte del resultat global amb un 
77,7 \% del codi D i un 60,7\% del codi E. És remarcable el descens de més de deu punts percentuals del codi E: aquests neologismes, només documentats en català perquè en castellà ja no es consideren unitats neològiques, són els més estables. De fet, un $7 \%$ de neologismes de la categoria $E$ tenen una freqüència mínima de cinc - mentre que aquest percentatge és d'un $0,54 \%$ en el codi $\mathrm{A}-\mathrm{i}$ un grau d'implementació en l'ús elevat, com podem veure en exemples com anticapitalista, gihadista, interanual, sobiranisme o xarxa social.

\section{Desviacions dels processos}

Per poder observar les desviacions dels processos que es produeixen en les diferents categories de vitalitat és necessària la referència dels resultats globals de cada procés. En la taula 3 presentem aquests resultats en dues columnes segons si tenen una productivitat alta $(\geq 10 \%)$ o baixa $(<10 \%)$ i, a continuació, ens fixarem en les desviacions que es produeixen en els processos més productius.

\begin{tabular}{l|l}
\hline Processos més productius (valor mitjà) & Processos menys productius (valor mitjà) \\
\hline Manlleu anglès $(16,5 \%)$ & Altres manlleus $(6,8 \%)$ \\
Sufixació $(13,5 \%)$ & Manlleu castellà $(5,6 \%)$ \\
Prefixació $(13,1 \%)$ & Composició $(4,6 \%)$ \\
Semàntic $(10,1 \%)$ & Conversió $(3,6 \%)$ \\
Sintagmació $(10 \%)$ & Truncació $(2,7 \%)$ \\
Composició culta $(10 \%)$ & Lexicalització $(1,9 \%)$ \\
& Altres $(1,3 \%)$ \\
\hline
\end{tabular}

Taula 3. Productivitat total dels processos d'innovació lèxica

Els manlleus de l'anglès presenten una gran variabilitat de percentatge segons la categoria de vitalitat. D’una banda, és molt baix a la categoria E $(6,6 \%)$ de neologismes ja documentats en les obres lexicogràfiques en castellà perquè, com és sabut, els manlleus són, per norma general, paraules menys diccionaritzables; de l'altra, en la categoria C, d'unitats documentades al mateix temps en català i en castellà, representen el $27,4 \%$ i, per tant, aquest resultat — que podem il·lustar amb una llarga llista de mots que fan referència a innovacions tecnològiques com e-mail, hashtag o app — és un indici de l'heteronomia del català i del castellà respecte de l'anglès, com veurem més endavant (§ 4.2.3). 
La sufixació també presenta una variabilitat que anuncia tendències en les diferents categories de vitalitat: el valor mitjà és del 13,5 \%, però puja fins al 20,3 \% en la categoria $\mathrm{A}$, la més autònoma, i baixa fins a l'11 \% en la $\mathrm{D}$ (neologismes documentats primer en castellà). En cap categoria la sufixació se situa per sota del $10 \%$, perquè és un recurs tan útil per al calc com per a la producció pròpia més creativa, i l'augment en la categoria $\mathrm{A}$ respon precisament a neologismes sufixats amb un caràcter clarament expressiu, com s'aprecia en l'anàlisi per categories i com avançàvem en els exemples de la taula 2 (comsemprisme, taradellejar, marranor, tofonada).

La prefixació és un procés neutre des del punt de vista de la vitalitat perquè trobem un percentatge semblant en totes les categories — les oscil·lacions respecte del valor mitjà del 13,1 \% són poc rellevants: $10,4 \%$ en les categories A i E, i $14,9 \%$ en la categoria C. En canvi, els neologismes semàntics presenten també contrastos importants que es fan evidents en els extrems: trobem un 4,9\% en la categoria $\mathrm{A}$, un $15,4 \%$ en la $\mathrm{E}$, i un valor mitjà del 10,1 \%. L'augment del valor en la categoria E s'explica pel caràcter altament diccionaritzable dels neologismes semàntics (baró, futurista i oxigenar). En canvi, caldrà observar en el detall dels exemples el motiu pel qual el percentatge baixa tant en la categoria $\mathrm{A}$, però puja molt en la B $(14,9 \%)$, que també és una categoria autònoma.

Dins dels neologismes per sintagmació també hi ha desviacions segons les categories: el valor mitjà és del $10 \%$ però en la categoria A baixa fins al 2,1\% i, en canvi, puja fins al $13,7 \%$ en el codi $\mathrm{D}$, en l'extrem heterònom de l'eix. I és que, com hem vist, les unitats heterònomes són més estables i s'hi troben unitats sintagmàtiques amb un caràcter denominatiu fort (bombolla immobiliària, noves tecnologies, línia vermella, mercat laboral, memòria històrica, novel·la negra), mentre que en el codi A la tendència és cap a un altre tipus de neologismes, en què la formació sintagmàtica no hi té un paper principal — tot i així, 
trobem sintagmes molt genuïns com ball de morratxes, mongeta del ganxet, nucli antic o pa de tempesta.

Finalment, amb relació a la composició culta, la desviació més remarcable respecte del $10 \%$ mitjà és el descens d'un $4,5 \%$ en les unitats que ja trobem al DLE, perquè són unitats poc diccionaritzables, sigui perquè es tracta de mots especializats (isquiosural, nutrigenòmica, rombencefalitis) o de mots utilitzats amb un valor expressiu que pretén causar impacte en l'interlocutor (eurofan, macroagenda, oscaròleg). ${ }^{\mathrm{xi}}$

La conclusió d'aquest apartat de resultats generals amb atenció especial a l'anàlisi de freqüència i de mecanismes d'innovació és clara: les dades indiquen tendències que diferencien les categories de vitalitat lèxica i que ens permeten entreveure quan i com el català és autònom o heterònom.

\subsection{Anàlisi per categories de vitalitat}

En l'apartat anterior mostràvem els resultats generals de les diferents categories de l'eix de vitalitat lèxica per veure en quin punt se situa actualment el català, $i$ hem volgut contrastar de manera transversal els aspectes de freqüència $i$ de productivitat dels processos d'innovació lèxica. Amb això ja hem obtingut una primera caracterització de les diferents categories, però ara volem, d'una banda, portar l'anàlisi al nivell dels exemples per afinar més aquesta caracterització i, de l'altra, amb l'objectiu de percebre més tendències, agrupar les cinc categories en les tres supracategories que ja hem vist: autonomia, convergència $\mathrm{i}$ heteronomia.

\subsubsection{L'autonomia del català}

El català innova lèxicament de manera pròpia i no pas aliena quan un neologisme ha aparegut en l'ús general — bàsicament de la premsa escrita— en català abans que en castellà, i això és el que trobem en un 17 \% dels casos, com hem vist a la figura 3 . Hem distingit dues situacions d'autonomia: quan encara no s'ha documentat la forma equivalent per al castellà 
(codi A), que representa un 4,3\% de les unitats, i quan s'han documentat totes dues, però la forma catalana s'ha documentat almenys dos anys abans que la castellana (codi B), amb un $12,7 \%$.

El primer que cal destacar, des del nostre punt de vista, és el fet que el català tingui un espai denominatiu propi, que davant la mundialització no només reaccioni —encara que sigui calcant, però fent servir les regles de la llengua—, sinó que demostri també la vitalitat suficient per formar paraules noves de manera autònoma en un percentatge encara representatiu. Com ja hem esmentat en l'apartat de resultats generals, els neologismes autònoms tenen una estabilitat menor i s'especialitzen en uns mecanismes concrets en què hi tenen més pes la sufixació i la composició patrimonial i, en canvi, hi tenen un pes menor els mecanismes propis de la neologia denominativa: la composició culta i la sintagmació. En els exemples següents podem veure que la funció d'aquestes unitats és de caràcter expressiu:

- Els comsempristes són aquells que de posar una cara nova en diuen canvi, però tot segueix igual de rovellat. [Butlletí Informatiu de l'ajuntament de Malgrat de Mar, 1/02/2016]

- Verhoeven (sentiu-lo parlar en holandès perquè cruifeja notablement) és d'aquells directors que han nascut del cinema més cru i independent $\mathrm{i}$ han sabut portar aquest bagatge moral al d'entreteniment. [Ara, 7/10/2016]

- En favor de la Marta direm que l'empanamenta li va enganxar al Dani Jiménez. Ell sempre té algun moment d'espessor. [Catalunya Ràdio, 11/02/2016]

- Sóc tan fan del Julio Iglesias que li porto un tapapets perquè se'l posi la seva senyora. [País $k m 0$ (La Xarxa), 2/08/2016]

En els primers exemples es pot observar com s'utilitzen diferents regles de sufixació per crear un efecte marcat, no tant pel sufix utilitzat com per la base adjuntada al sufix. En el primer cas, comsemprista és només un dels exemples nombrosos que trobem amb -isme i ista (diacritista, montblanquinisme, puigdemonista, puta-ramonetista, sitgetanisme) i els altres casos demostren usos expressius que pretenen cridar l'atenció del lector i que sovint 
s'associen al registre col·loquial (ciberplatja, despentinament, kitschejar, marranor, postpolvoró, taradellejar, trumpeter, twitterià). I el mateix efecte produeixen alguns neologismes formats per composició patrimonial, com podem veure en l'exemple de tapapets i en d'altres com tiracanyes, correcampus, pacteclosques, wonderconsell.

Però quan el català innova de manera pròpia, també ho fa amb mots no connotats pragmàticament per denominar el que és més local i tradicional. Els exemples següents provenen tots d'un espai radiofònic que cada estiu segueix els costums d'una part del territori català:

- Quan acaba el segon salt de plens tenim els tiravolts i surten les dues guites a la plaça i els gegants ballen. [País km0 (La Xarxa), 2/09/2016]

- Farem un repicó curt i un bilandó, que és el toc a la festa major. [País km0 (La Xarxa), $2 / 08 / 2016]$

- Esbaiolar-se vol dir esbargir-se, passar-ho bé, i això és el que pretén aquest festival. [País $k m 0$ (La Xarxa), 22/07/2016]

- El pa de tempesta no és comestible i la seva tradició arrenca del segle XV: es posa darrere la porta o la finestra perquè ens guardi de qualsevol mal. [País km0 (La Xarxa), 26/08/2016]

- Un oki és una fruita molt famosa d'aquí, d'Alcarràs. [País km0 (La Xarxa), 14/07/2016]

Com es pot observar, aquests mots no són nous, però no figuren en el diccionari precisament pel caràcter marcadament tradicional, local i sovint referit a la gastronomia i a la cultura popular. No són exemples, doncs, que demostrin l'autonomia del català en la innovació lèxica actual, sinó que parlen del manteniment de la cultura pròpia i dels seus mots.

\subsubsection{La convergència del català $i$ el castellà}

Hem denominat convergència la categoria intermèdia de l'eix d'autonomia a heteronomia, on trobem els neologismes que s'han documentat alhora en català $i$ en castellà. Com hem vist en l'anàlisi de resultats generals, aquesta categoria (codi C) representa el 15,9\% del total de neologismes analitzats $\mathrm{i}$, des del punt de vista de la freqüència, presenten una 
estabilització una mica superior a la mitjana —amb un $6 \%$ menys d'hàpaxs que en els resultats globals. En analitzar les desviacions dels mecanismes d'innovació d'aquesta categoria respecte dels valors mitjans, s'observa que els manlleus de l'anglès sumen un $27,4 \%$, onze punts per sobre del percentatge global.

Efectivament, la presència de manlleus de l'anglès és el tret més característic d'aquest bloc de neologismes. En la dècada dels anys 90 van ser una llista interminable de manlleus referits a la música moderna i al món de l'espectacle, com blockbuster, chill out, dance, dj, drag queen, friqui, indie, performer, reality show o techno, i en la primera dècada del segle XXI, van començar a proliferar els manlleus — i els calcs— de l'àmbit de les noves tecnologies (ciberatac, viral i altres), però no van aparèixer massivament fins a la segona dècada, amb unitats com hashtag, selfie, ${ }^{\text {xii }}$ smart city, tablet, trending topic, etcètera. I és que la presència de manlleus — fonamentalment de l'anglès — en el català quotidià presenta una tendència a l'alça que ja ha estat establerta en treballs anteriors en mig punt anual els darrers trenta anys. ${ }^{\text {xiii }}$

Aquesta coincidència d'aparició de manlleus al mateix temps en català i en castellà és un argument a favor de l'autonomia del català respecte del castellà, però també és un cas que demostra l'heteronomia de totes dues llengües respecte de l'anglès. Aquesta dependència de l'anglès es veu també en formes no manllevades sinó calcades, quan català i castellà reaccionen alhora amb formes alternatives com quota de pantalla i cuota de pantalla, que es documenten totes dues l'any 1995 per evitar el share, recollit des del 1993 en textos catalans i castellans, o tauleta i tableta, documentades l'any 2010 per evitar el manlleu tablet, ja implementats en l'ús de totes dues llengües uns anys abans. El mateix escenari es repeteix, amb més o menys coincidència en el temps, amb altres calcs com itinerància (cast. itinerancia) per roaming o micromecenatge (cast. micromecenazgo) per crowdfunding. 
L'heteronomia del català i el castellà respecte de l'anglès que acabem de veure en tot allò que ens ve del món modern nord-americà s'observa també en el món europeu comunitari, on la lingua franca és també l'anglès, si bé en aquest cas les unitats ja han estat uniformement traduïdes: eurocambra, europarlament, euroescepticisme, euroordre, eurofóbia, etcètera. Són exemples que demostren que el castellà no ha estat l'intermediari entre l'anglès i el català, sinó que totes dues llengües han importat i copiat directament de l'anglès.

Altres vegades, però, aquesta heteronomia és molt més discreta, quan el calc és menys evident perquè no s'identifica l'aparició d'un referent extern; són casos en què fàcilment defensaríem l'autonomia del català i el castellà respecte de l'anglès, però la mirada documental, buscant en grans corpus el moment d'aparició d'un neologisme en les diferents llengües, ens retorna a la realitat heterònoma: a continuació podem veure com neologismes aparentment propis, com multiculturalisme, revisitar o refinançar — neologismes escollits a l'atzar dins del bloc de neologismes que presenten convergència entre català i castellà- van aparèixer en la premsa catalana i castellana molt després que en la premsa nord-americana.

\begin{tabular}{|c|c|c|}
\hline Català & Castellà & \\
\hline El programa $n$ & Parecería & Trudeau \\
\hline $\begin{array}{l}\text { de multiculturalisme va ser } \\
\text { aprovat pel govern central el } \\
\text { 1988. [Avui, 20/01/1991] }\end{array}$ & $\begin{array}{l}\text { querido evidenciar con } \\
\text { maligno propósito el } \\
\text { disparate que envuelve esa } \\
\text { boga actual de un pretendido } \\
\text { multiculturalismo. [El País, } \\
\text { 2/01/1992] }\end{array}$ & $\begin{array}{l}\text { Winnipeg to explain } \\
\text { multiculturalism program to } \\
\text { meeting of Ukrainian Cong. } \\
\text { [New York Times Abstracts, } \\
10 / 10 / 1971]\end{array}$ \\
\hline $\begin{array}{l}\text { Villalba, } \\
\text { l'assassí que torna al lloc del } \\
\text { crim, ha revisitat la seva } \\
\text { pròpia pintura [...]. [Avui, } \\
\text { 8/09/1994] }\end{array}$ & $\begin{array}{l}\text { Todos ellos }[\ldots] \\
\text { aman los géneros, aunque } \\
\text { revisitados y con punto de } \\
\text { vista propio. }[\text { El Pais, } \\
28 / 06 / 1994]\end{array}$ & $\begin{array}{l}\text { To some, the } \\
\text { situation is Charles Dickens } \\
\text { revisited, nineteenth century } \\
\text { justuce for juveniles who } \\
\text { stray onto the crooked path } \\
\text { of delinquency. [The Globe } \\
\text { and Mail, 10/12/1977] }\end{array}$ \\
\hline \begin{tabular}{l}
\multicolumn{4}{c}{ Concretament durant } \\
els sis primers mesos de \\
l'any el Tresor haurà de \\
refinançar 8,59 bilions de \\
pessetes. $[$ Avui, $23 / 01 / 1995]$
\end{tabular} & $\begin{array}{l}\text { Ello obligará a } \\
\text { realizar una operación } \\
\text { crediticia para refinanciar la } \\
\text { deuda y los intereses de los } \\
\text { últimos tres años que el } \\
\text { consistorio todavía adeuda. } \\
\text { [La Vanguardia, } 13 / 03 / 1995]\end{array}$ & $\begin{array}{l}\text { Holders of almost } \\
\text { \$2-billion in maturing notes } \\
\text { and bonds reject Treas offer } \\
\text { to refinance them at highest } \\
\text { interest rates in } 103 \text { years. } \\
\text { [New York Times Abstracts, } \\
6 / 06 / 1969]\end{array}$ \\
\hline
\end{tabular}


Taula 4. L'heteronomia oculta del català i el castellà respecte de l'anglès

El cas de multiculturalisme, per exemple, es documenta per a l'anglès des de principis dels anys 70 , com es pot veure a la taula 4 , tot i que no es documenta en català $i$ castellà fins a principis dels anys $90,{ }^{\text {xiv }}$ que és quan augmenta molt considerablement la freqüència d'aparició d'aquest neologisme en anglès. El mateix passa amb els altres exemples: paraules que podrien haver estat encunyades en qualsevol d'aquestes llengües i en qualsevol moment es posen «en circulació» en un moment i per un motiu determinats i és l'anglès qui dona el tret de sortida. Així doncs, l'heteronomia del català i el castellà respecte de l'anglès no només es troba en el fet que apareguin paraules noves, sinó en el fet que paraules possibles i, en alguns casos ja existents, augmenten la freqüència quan ho marca l'anglès.

En canvi, quan acostem el zoom a la realitat més propera, trobem el punt de convergència en català i castellà, perquè són dues llengües que comparteixen un mateix terreny, és a dir, té incidència en els àmbits polític i esportiu estatals i catalans, així com en tot allò relacionat amb la vida social i econòmica compartida; en són exemples caixa $b$, ecosocialista, gentrificar, joancarlisme, indignat i madridisme.

\subsubsection{L'heteronomia del català}

Com hem vist en l'eix de vitalitat lèxica, l'heteronomia representa el 66,8\% dels neologismes recollits en el corpus. Aquest fet ens indica que, com a mínim en dos terços de l'activitat d'innovació lèxica, el català reacciona al coneixement que arriba ja denominat traduint i proposant una denominació calcada i equivalent, una denominació explicable a partir de la llengua i que, per norma general, està ben formada, però que en el fons demostra passivitat lingüística. Però certament, la passivitat és molt més evident en el $28 \%$ de manlleus, bàsicament de l'anglès $(13,9 \%)$, però també del castellà $(7,7 \%)$ i d'altres llengües $^{\mathrm{xv}}(6,2 \%)$. 
Amb tot, aquesta passivitat de què parlem és fins a cert punt justificada, ja que la llengua catalana, com la resta de llengües, no es pot permetre un distanciament elevat de l'expressió denominativa més genèrica i global. Qualsevol llengua que pretengui distanciarse totalment —o majoritàriament— de les solucions denominatives universals que va marcant l'anglès, corre el risc d'esdevenir poc adequada per a la comunicació i, en definitiva, que els parlants la percebin com a ineficaç des del punt de vista comunicatiu.

Respecte del bloc de l'heteronomia, sobretot ens centrem en el codi D, que representa el 40,8\% dels casos, i parem especial atenció en les desviacions que hi ha respecte dels processos de formació de mots i el caràcter fortament denominatiu d'aquests neologismes. En el codi $\mathrm{D}$ cal destacar la gran presència de construccions sintagmàtiques $(13,7 \%)$, que representen una desviació positiva del 3,7\% respecte del total d'unitats $(10,7 \%)$, com podem veure a la figura 5. Igualment, també trobem desviacions en positiu en la composició culta $(12,4 \%)$, que supera les dades generals un $2,3 \%$, i els manlleus de l'anglès, que arriben al $18,7 \%$ dels casos, és a dir, un 2,2\% més que en les dades totals — tot i que els manlleus de l'anglès tenen una desviació positiva en tots els codis, menys en les categories B i E.

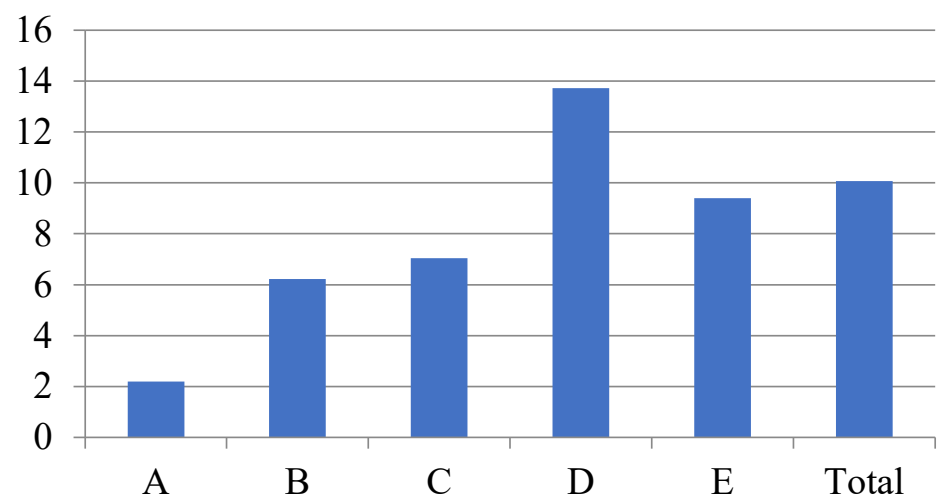

Figura 5. Tendència a l'heteronomia de les unitats sintagmàtiques

D'altra banda, cal destacar que la major part d'aquestes unitats tenen una càrrega denominativa molt marcada, com s'observa en unitats del tipus automòbil elèctric, cos tècnic, dismòrfia i networking. Fins i tot, en alguns casos tenen un caràcter tècnic i especialitzat, com 
a cloud computing, epigenoma, exaflop i geolocalització. I, a més a més, són mots que generalment provenen d'àmbits internacionals, com podem veure amb bosó de Higgs, ciberagent o trail, fins i tot si són compostos aparentment patrimonials (fotollibre, quilòmetre zero) o mots derivats (hipersexualitzar, poliamor, usabilitat, viralitat).

A partir d'aquí, doncs, ens podem preguntar una altra vegada si realment aquesta heteronomia de la llengua catalana ho és respecte del castellà o respecte de l'anglès, en la mesura que moltes unitats provenen de la segona llengua. Al cap i a la fi, com ja hem esmentat al principi d'aquest treball, avui dia la majoria de llengües comparteixen un marc denominatiu en què la llengua anglesa s'imposa a la resta, i la llengua catalana no n'és una excepció. Els exemples que mostrem a continuació reforcen la idea de l'heteronomia respecte de l'anglès perquè el castellà és la llengua intermediària entre el mot anglès (que apareix primer) i el mot català (que apareix més tard).

\begin{tabular}{lccc}
\hline Neologisme & Anglès & Castellà & Català \\
\hline bariàtric & 1977 & 2003 & 2007 \\
\hline customització & 1972 & 2000 & 2003 \\
\hline glocal & 1984 & 1997 & 2002 \\
\hline rock de garatge & 1982 & 1996 & 2003 \\
\hline viralitzar & 1987 & 2008 & 2013 \\
\hline neoliberal & 1981 & 1994 & 2000 \\
\hline
\end{tabular}

Taula 5. Primera documentació de neologismes del codi $\mathrm{D}^{\mathrm{xvi}}$

Finalment, tractem les dades relacionades amb el codi E, és a dir, aquelles unitats que són neològiques en català, però que en castellà ja són al diccionari normatiu, que representen el $26 \%$ dels casos. Dins aquest conjunt, sobretot trobem mots derivats (antiviral, col·laboratiu, empatitzar, incivisme) i casos de resemantització (clínex, dispositiu, oxigenar, sobrecàrrega), que són unitats molt diccionaritzables. A partir de les dades d'aquesta categoria podem constatar que la llengua castellana no només té una situació sociolingüística positiva, sinó que l'acadèmia de la llengua hi actua consegüentment amb una política lexicogràfica que permet incloure mots d'innovació pròpia, però també mots que són fruit d'un calc o d'un manlleu —en són exemples best-seller, chakra, halal, sex symbol i wifi. Tots 
aquests casos són exemples de com el DLE incorpora les novetats lèxiques regularment, com podem veure en mots recents del tipus buenismo, dron o posverdad.

Contràriament, en català existeix una política lexicogràfica diferent per part de l'Institut d'Estudis Catalans (IEC), més restrictiva, que sovint és criticada per diferents sectors de la societat i dels professionals de la llengua, per la distància excessiva entre ús i norma — que pot provocar distanciament dels parlants respecte de la llengua. Això no obstant, es tracta d'una acció coherent amb la situació sociopolítica de la llengua catalana, atès que és encara una llengua minoritzada i en procés de normalització lingüística especialment en determinades àrees del domini lingüístic. Així doncs, tot i la prudència de l'IEC en les actualitzacions del diccionari normatiu, hem de tenir en compte que no podem esperar una actuació semblant a la de la Real Academia Española, en la mesura que són dues realitats sociolingüístiques diferents, tant pel que fa al nombre de parlants, com respecte de la situació politicosocial.

\section{Conclusions}

Al llarg d'aquest article hem volgut comprovar, a través d'un corpus de neologismes representatiu, en quin punt de l'eix de vitalitat lèxica se situa la llengua catalana avui dia, superant metodològicament els treballs que s'han dut a terme en aquesta línia. Els resultats indiquen clarament que el català tendeix a l'heteronomia. L'anàlisi dels neologismes heterònoms posa de manifest que el català omple els buits denominatius traduint els neologismes d'altres llengües, la qual cosa evidencia la situació de passivitat lingüística del català. Aquest fet s'accentua amb la presència de manlleus, sobretot de l'anglès, ja que moltes de les realitats noves que ens arriben provenen del món anglosaxó. D’altra banda, tampoc no es poden obviar les unitats neològiques que han estat incorporades al diccionari normatiu en castellà, perquè en català, tot i que la majoria d'aquests neologismes presenten 
estabilitat en l'ús i tenen una intenció clarament denominativa, encara es manté una certa prudència a l'hora d'incloure'ls al diccionari de l'IEC.

Però els resultats també indiquen que el català té marge per a la innovació lèxica pròpia, amb mots que tenen un fort caràcter local o bé una càrrega clarament expressiva, que pretén causar un efecte en el parlant. Podem afirmar, doncs, que actualment el català no se situa en cap dels dos pols de vitalitat lèxica, ni tampoc en un punt intermedi entre autonomia $\mathrm{i}$ heteronomia: el català està copiant — de l'anglès i del castellà — al mateix temps que manté un petit espai d'innovació lèxica pròpia. Seran les institucions, els professionals de la llengua i dels mitjans de comunicació i, en definitiva, els parlants qui decidiran en quin punt de l'eix de vitalitat lèxica s'ha de trobar el català en el futur.

Quant a la convergència, es tracta d'un espai en el qual el català innova al mateix temps que el castellà mitjançant formes alternatives, però de tota manera respon a un cas d'heteronomia respecte de l'anglès. Quan es volen denominar conceptes nous, propis d'àmbits internacionals, el català intenta mantenir la coherència denominativa amb la resta de llengües i, d'aquesta manera, pretén defugir el manlleu.

En definitiva, el català és una llengua que, tot i que no és hegemònica en el món denominatiu actual — perquè rep la influència principalment del castellà, i aquesta de l'anglès_-, avança i s'adapta davant la presència constant de paraules noves que apareixen en l'ús i que es van introduint en el cabal lèxic dels parlants. Al cap i a la fi, en el món globalitzat en què vivim, és inevitable el contacte i la interferència entre llengües, perquè «tots parlem de les mateixes coses amb un marge de diferència força petit» (Freixa 2017: 44). En aquest panorama, el català ha de trobar la manera d'aconseguir l'estabilitat entre l'autonomia i l'heteronomia i mantenir, així, la voluntat de seguir creant paraules noves més enllà del marge de la innovació lèxica pròpia. 


\section{Referències bibliogràfiques}

Adelstein, A. "Banalización de términos con formantes grecolatinos". Actas del V Simposio Iberoamericano de Terminología Riterm. Riterm. Mèxic: Riterm, 1996. 12-17.

Badia i Margarit, A. M. "Risc i certesa de la neologia". La neologia en el tombant de segle. Cabré, M. T. et al. Barcelona: IULA-UPF, 2000. 17-27.

Cabré, M. T. "La neologia com a mesura de la vitalitat interna de les llengües". La neologia en el tombant de segle. Cabré, M. T. et al. Barcelona: IULA-UPF, 2000. 85-108.

Cabré, M. T. "Introducció: la importància de la neologia per al desenvolupament sostenible de la llengua catalana”. Llengua catalana i neologia. Observatori de Neologia. Barcelona: Meteora, 2004. 17-45.

Cabré M. T.; Bayà, M. R.; Bernal, E.; Freixa, J.; Solé, E.; Vallès, T. "Evaluación de la vitalidad de una lengua a través de la neología: a propósito de la neología espontánea y de la neología planificada”. La fabrique des mots. La néologie ibérique. Chevalier, J-C.; Delport, M-F. París: Presses de l’Université de Paris-Sorbonne, 2000. 91-130.

Cabré, M. T.; Freixa, J.; Solé, E. (ed.) La neologia en el tombant de segle. Barcelona: IULAUPF, 2000.

Cabré, M. T.; Freixa, J.; Solé, E. “Anàlisi contrastiva de la innovació lèxica en català i en castellà”. Caplletra 30 (2001): 199-212.

Chambers, J. K.; Trudgill, P. Dialectology. Cambridge: Cambridge University Press, 1998.

[Factiva] Dow Jones (1989- ). Factiva. Nueva York: Down Jones \& Company. En línia a $<$ https://global.factiva.com>.

Fernández, J. Neología y neologismo en español contemporáneo. Granada: Don Quijote, 1982.

Fischer, R. "Lexical institutionalization reconsidered". The Evolution of Englishes: The Dynamic Model and beyond, John Benjamins Publishing Company (2014): 448-469. 
Freixa, J. "La interferència en la innovació lèxica del català: anàlisi dels neologismes amb ciber- i homo-“. Revista de Llengua i Dret 51 (2009): 259-281.

Freixa, J. "La implantació del lèxic normatiu: estudi complementari del lèxic implantat no normatiu”. Treballs de Sociolingüistica Catalana 25 (2015): 65-80.

Freixa, J. “La neologia en societat: verba sequuntur”. Caplletra 59 (2015): 185-195.

Freixa, J. "Paraules per al futur". Mots d'avui, mots de demà. Observatori de Neologia (ed.). Institut de Lingüística Aplicada. Universitat Pompeu Fabra; 2016. p. 13-18.

Freixa, J. "Tendències actuals en neologia catalana: innovar o copiar?". Creació terminologica: de Llull a les xarxes socials. Espais terminologics 2016. Termcat. Barcelona: Termcat, 2017. 35-52.

Freixa, J. "Augment constant de la presència de manlleus en la premsa catalana: una conseqüència de la mundialització?’. Treballs de Sociolingüistica Catalana 29 (2019, en premsa).

Freixa, J.; Bernal, E.; Cabré, M. T. (ed.). La neologia lèxica catalana. Barcelona: Institut d'Estudis Catalans. Secció Filològica; 2015.

Hohenhaus, P. "Lexicalization and institutionalization". Handbook of word-formation. Pavol Štekauer \& Rocheller Lieber (ed.). Dordrecht: Springer (2004): 353-373.

Humbley, J. "La néologie: avenir des langues". La neologia en el tombant de segle. Cabré, M. T. et al. Barcelona: IULA-UPF, 2000. 175-180.

Rull, X. Els estrangerismes del català. Com són i per què en tenim. Una aproximació social i lingüística. Tarragona: Publicacions URV, 2008.

Sinner, C. (2006). «Influències lingüístiques com a senyal de vitalitat d'una llengua». Actes del XIVè Col·loqui Internacional de Llengua i Literatura Catalanes. Universitat Eötvös Loránd, Budapest, 4-9 de setembre de 2006. Barcelona: PAM, 2006.

Trudgill, P. Dialects in contact. Oxford: Blackwell, 1986. 
Rogers, E. Diffusion of innovations. New York: Simon and Schuster; 2010.

\footnotetext{
${ }^{i}$ L'elaboració d'aquest article ha comptat amb el suport del projecte NEÓMETRO «La medición de la neologicidad y la diccionariabilidad de los neologismos del español», del Ministerio de Economía y Competitividad (ref. FFI2016-79129-P), finançat per l'Agencia Estatal de Investigación (AEI) i el Fons Europeu de Desenvolupament Regional (FEDER).

ii Volem agrair a Jorge Diz, Cèlia Fenollosa, Pau Oró i Víctor Ruiz la seva participació en la primera fase de treball de la línia de recerca que ha culminat amb aquesta publicació.

iii L'Observatori de Neologia (OBNEO) és un grup de recerca de la Universitat Pompeu Fabra de Barcelona que, des del 1988, analitza el fenomen de l'aparició de paraules noves o neologismes en l'ús, tant pel que fa al català com al castellà. Fabra (https://www.upf.edu/web/obneo).

iv $\mathrm{Cal}$ tenir en compte que no totes les unitats neològiques augmenten el cabal lèxic, sinó que algunes simplement el renoven i l'actualitzen (Fernández 1982: 28).

` Segons Rull (2008: 201), «un nombre excessiu de manlleus pot distorsionar la fesomia d'una llengua. Així, un text farcit de paraules que no són del sistema [...] no és indici precisament de salut de la llengua».

${ }^{\text {vi }}$ En els observatoris de neologia es consideren neologismes les paraules que es documenten en l'ús (especialment de premsa general) i que no es documenten en els diccionaris de referència.

vii Ens referim a la forma castellana previsible a partir del neologisme català (manlleu, semàntic, sintagmàtic, derivat, etcètera) i només quan la forma castellana no es desvia àmpliament de la catalana.

viii Factiva és una base de dades que inclou un gran volum d'informació de premsa en més de vint-i-cinc idiomes i dos-cents països.

ix Sigui com sigui, no hem d'oblidar que el català i el castellà són dos sistemes lingüístics romànics, de manera que tenen molts de punts en comú $i$, per tant, la convergència és esperable.

${ }^{x}$ Atès que el contrast es fa per anys i no per dates exactes, s'ha considerat que la diferència mínima en el temps havia de ser de dos anys. Hem estudiat l'impacte d'aquesta decisió metodològica i hem comprovat que provoca un biaix menor: el $52 \%$ dels exemples es van documentar el mateix any; el $30 \%$, un any abans en castellà i un $18 \%$, un any abans en català.

${ }^{x i}$ Aquests casos són els compostos cultes banalitzats, segons Adelstein (1996) i Cabré et al. (2008), entre d'altres.

xii Segons Freixa (2017: 50), «hi ha paraules que arriben totalment lligades a un moment concret i, encara que selfie ja feia anys que existia, es va fer realment popular amb la foto del president Obama amb altres mandataris en l'homenatge a Nelson Mandela l'any 2013».

xiii L'any 1989, quan l'Observatori de Neologia va començar la tasca de buidatge de textos de premsa per detectar les paraules noves que hi apareixen, el percentatge de manlleus era del 17,6\% i l'any 2017 el percentatge de manlleus va arribar al màxim històric del 32,5\%. En tres dècades, doncs, l'espai de formació pròpia de paraules noves s'ha reduït notablement $i$ a un ritme de mig punt anual de mitjana (Freixa, en premsa).

xiv Cal tenir en compte que l'OBNEO inicia la fase de buidatge a partir d'aquesta dècada $i$ que la base de dades Factiva només inclou dades a partir del 1994 en castellà i del 2000 en català.

${ }^{x v}$ Entre aquests sistemes lingüístics trobem el francès, l'italià, l'alemany, el japonès, l'àrab i una vintena més.

${ }^{\text {xvi }}$ Aquesta taula s'ha elaborat a partir de la base de dades Factiva.
} 